\title{
Comprehensive assessment of regional selenium resources in soils based on the analytic hierarchy process: Assessment system construction and case demonstration
}

\author{
Ruoyu Liang a,b , Shuai Song ${ }^{\mathrm{a}}$, Yajing Shi ${ }^{\mathrm{c}}$, Yajuan Shi ${ }^{\mathrm{a}, *}$, Yonglong Lu ${ }^{\mathrm{a}, \mathrm{b}}$, Xiaoqi Zheng ${ }^{\mathrm{d}}$, Xiangbo Xu ${ }^{\mathrm{d}}$, \\ Yurong Wang ${ }^{c}$, Xuesong Han ${ }^{c}$ \\ a State Key Laboratory of Urban and Regional Ecology, Research Centre for Eco-Environmental Sciences, Chinese Academy of Sciences, Beijing 100085, China \\ ${ }^{\mathrm{b}}$ University of Chinese Academy of Sciences, Beijing 100049, China \\ c School of Biomedical and Chemical Engineering, Liaoning Institute of Science and Technology, Benxi 117004, China \\ ' School of Environment E Natural Resources, Renmin University of China, Beijing, 100059, China
}

\section{H I G H L I G H T S}

- A comprehensive assessment of regional selenium resources was constructed by AHP.

- Soil selenium, nutrient and environmental quality were indexes in criterion layers.

- The criterion was classified by summing critical values in standards with weights.

- The comprehensive evaluation system of selenium was classified into 5 grades.

- Priority areas for developing seleniumrich agriculture were identified in Boshan.

\section{A R T I C L E I N F O}

\section{Article history:}

Received 26 April 2017

Received in revised form 19 June 2017

Accepted 19 June 2017

Available online 30 June 2017

Editor: F.M. Tack

\section{Keywords:}

Selenium resources

AHP

Regional assessment

Selenium-rich agriculture

\section{G R A P H I A B S T R AC T}

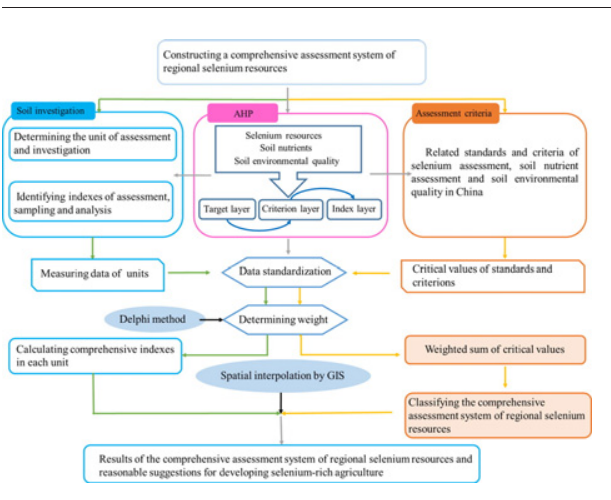

\section{A B S T R A C T}

The redundancy or deficiency of selenium in soils can cause adverse effects on crops and even threaten human health. It was necessary to assess selenium resources with a rigorous scientific appraisal. Previous studies of selenium resource assessment were usually carried out using a single index evaluation. A multi-index evaluation method (analytic hierarchy process) was used in this study to establish a comprehensive assessment system based on consideration of selenium content, soil nutrients and soil environmental quality. The criteria for the comprehensive assessment system were classified by summing critical values in the standards with weights and a Geographical Information System was used to reflect the regional distribution of the assessment results. Boshan, a representative region for developing selenium-rich agriculture, was taken as a case area and classified into Zone I-V, which suggested priority areas for developing selenium-rich agriculture. Most parts of the North and Midlands of Boshan were relatively suitable for development of selenium-rich agriculture. Soils in south fractions were contaminated by $\mathrm{Cd}$, PAHs, HCHs and DDTs, in which it was forbidden to farm. This study was expected to provide the basis for developing selenium-rich agriculture and an example for comprehensive evaluation of relevant resources in a region.

(c) 2017 Elsevier B.V. All rights reserved.

\footnotetext{
* Corresponding author.

E-mail address: yajuanshi@rcees.ac.cn (Y. Shi).
} 


\section{Introduction}

As an essential nutrient element, selenium was confirmed to have many benefits in human health, such as improving immunity, delaying senescence, preventing cancer and cardiovascular disease (Hatfield et al., 2014; Hughes et al., 2015; Stolzoff and Webster, 2015). Many epidemic diseases, such as Keshan disease, were caused by selenium deficiency in soils (Listed, 1979; Loscalzo, 2014). Previous studies focused on ecological risk of selenium for human health or selenium deficiency risk in populations (BY and XL, 2000; Skalny and Burtseva, 2015) and on how to replenish selenium. People may solve the self-demand for selenium by eating agricultural Se-enriched products. However, an overdose of selenium caused toxicity on living organisms, which may also have potential risks in ecosystems (Huang et al., 2009; Zhang et al., 2008).

Soils are the basis of plant growth and supply water and essential mineral elements, including selenium. In order to increase the concentrations of selenium in crops and vegetables, the farmers usually choose to do farming in some seleniferous soils, and fertilizers enriched with selenium could be another option to increase selenium concentrations in soils which lack selenium (De Temmerman et al., 2014). The investigation and assessment of selenium resources in soils could be a good guide to develop selenium-rich agricultural bases, which addresses the demand for selenium. However, past studies focused on a single index evaluation of selenium resources in farmlands (Li et al., 2006; Yang et al., 2016). Compared with single-index assessment, the multiindex assessment represents the states of soils more systematically and comprehensively. The growth of crops was affected by many factors, such as soil nutrients and environmental quality. It is necessary and meaningful to investigate and assess selenium in soils regionally and comprehensively.

The Analytic Hierarchy Process (AHP) is a multi-target decision method, which decomposes complex problems into different elements and classifies these elements into different levels (Saaty, 1980; Saaty, 2005; Saaty, 2008). AHP was usually applied to make a decision to select a suitable site with different purposes for environmental management (Hajeeh and Al-Othman, 2005; Vahidnia et al., 2009; Wang et al., 2009). The AHP approach was also adopted by many researchers for agricultural decisions (Alphonce, 1997). For example, the sites were chosen for agricultural management practices, such as forage fields, based on AHP (Sun et al., 2009). Therefore, AHP could be a promising tool to assess selenium resources and select sites for development of selenium-rich agriculture.

This study planned to combine a specialized analysis with visualization tools to assess selenium resources on a regional scale. Based on the AHP and the Geographic Information System (GIS), a comprehensive assessment system of regional selenium resources was constructed through considering three aspects: selenium resources, soil nutrients, and environmental quality. In this way, soil nutrient factors, selenium and pollutant content in soils were analyzed and determined. This study is expected to provide the basis for development of seleniumrich agriculture, but also to provide a reference example for the comprehensive evaluation of regional environmental resources.

\section{Assessment methods and procedures}

\subsection{Frame for regional selenium resources assessment}

The main aim of this study was to evaluate selenium resources in soils and construct a comprehensive evaluation system of regional selenium resources based on AHP. The general steps of AHP are to establish the analytic hierarchy structure, construct the judgment matrix to determine the weight of each index, and calculate the weight of each evaluation factor. Firstly, we need to determine the evaluated unit of a regional area. At the same time, the analytic hierarchy process was used to establish hierarchical structure of the assessment system and to identify each index level. The soil samples were collected and analyzed from each unit in the region to obtain measured data. Then, these measured data were standardized to eliminate effects of different dimension. In order to determine weights of each index level, experts and scholars with a background in ecology or environmental science were invited to answer the questionnaires to determine the weight of each index using the AHP and Delphi method. The comprehensive assessment index of each unit was calculated. The criteria proposed by experts and scholars and the national standards of China offered references for establishing assessment criteria of regional selenium resources. Next, the comprehensive evaluation system of regional selenium resources was classified into different grades. The measured data were standardized using a non-dimensionalized method, and then the standardized values were interpolated by a geographic information system (ArcGIS 10.2) to reflect spatial distribution characteristics on a regional scale. According to sampling distribution and the size of samples, the suitable spatial interpolation method was adopted. When sample points normally follow the uniform distribution and the size of sample is relatively large, inverse distance weighting (IDW) will be adopted. According to the assessment criteria, evaluated areas were classified into corresponding zones and spatial distribution maps were produced to reflect the evaluation results. Through analyzing the evaluation results, reasonable suggestions were provided for the development of selenium-rich agricultural soils. A flow chart showing the research process is seen in Fig. 1.

\subsection{Establishing hierarchical structure}

To develop selenium-rich agriculture, we need to consider the content of selenium, environmental quality and soil nutrients, which are important factors that affected the growth of selenium-rich crops and the selenium content in plants. According to the principles of scientific, feasibility, compatibility and comprehensiveness of the analytic hierarchy process, indicators were selected and the hierarchical structure of the assessment system was established. The analytic hierarchy process usually contains three levels: target layer, criteria layer and index layer. The target layer was the comprehensive evaluation system of regional selenium resources. This study aimed to evaluate selenium resources in the region generally and scientifically. The selenium content, soil nutrients and environmental quality were chosen as indexes in the criterion layers of the hierarchical structure. Selenium was the subject of assessment and it was considered necessary and meaningful to evaluate selenium content in soils. In general, high soil nutrient content promotes crops growth and increases the volume of crops production. The good state of soil environmental quality is the guarantee of food safety as pollutants in soils can enter the human body through the food chain, which may cause human health problems (Gergen and Harmanescu, 2012; Khan et al., 2008). Therefore, soil environmental quality should be taken into account and chosen as an index in the comprehensive evaluation system of regional selenium resources.

In the criteria layer, the total selenium content in surface soils was selected as an indicator of the index layer. The total selenium content in surface soils was the result of the weathering of the parent material and the enrichment of the plants, which was regarded as an indicator that reflects selenium content in a region. Except total selenium content, bioavailable selenium is also related to the enrichment or deficiency of selenium. However, since the classification of bioavailable selenium is still controversial according to different extraction methods (Tolu et al., 2011; Li et al., 2016) and evaluation systems and standards of bioavailable selenium remain to be updated, bioavailable selenium was not chosen as an evaluation index. In the criteria layer of soil fertilizer, the content of soil organic matter, soil clay and soil nitrogen were chosen as indexes of the index layer. These environmental factors not only affect the plant growth, but also have impacts on effectiveness and speciation of selenium (Johnsson, 1991; Borowska et al., 2013; Supriatin et al., 2015). Soil organic matter, soil clay and soil nitrogen are important 


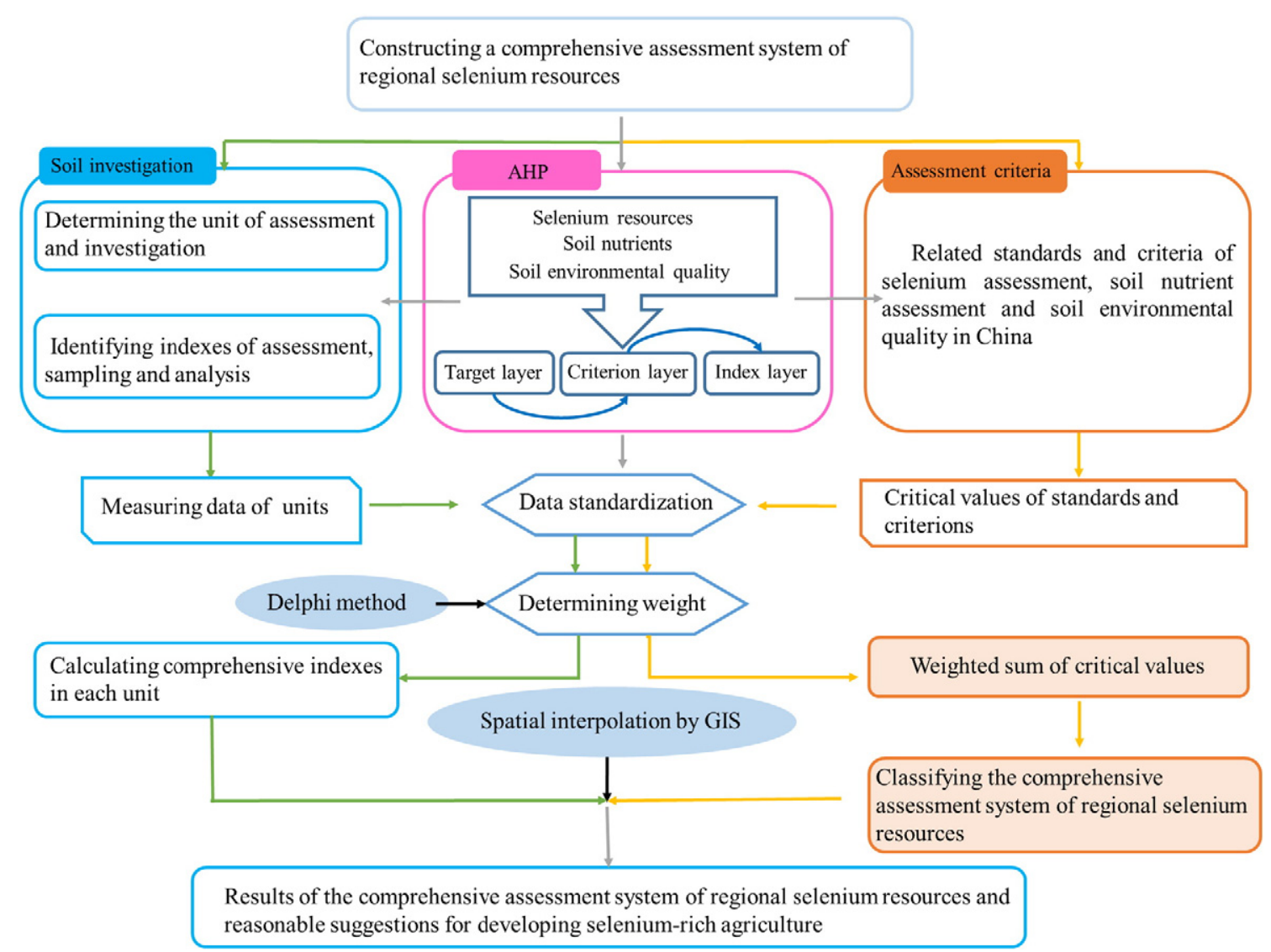

Fig. 1. Flow chart of comprehensive assessment of regional selenium resources.

indicators of soil nutrient and fertility, which play important roles in improving soil physical and chemical properties that affect growth. Besides, soil organic matter, total nitrogen, and clay content may affect the absorption of selenium in plants (Supriatin et al., 2016). Under the criteria layer of soil environmental quality, the contents of heavy metals, polycyclic aromatic hydrocarbons (PAHs) and pesticides (DDTs and $\mathrm{HCHs}$ ) were identified as indicators of the index layer. These pollutants are basic control indicators in environmental quality evaluation standards for farmland of edible agricultural products and environmental quality standards for soils (State Standard of China, 2006). It is also noteworthy that the compound pollution of pesticide, heavy metal and polycyclic aromatic hydrocarbons were found in many areas of China (Shen et al., 2005; Sun et al., 2014). Previous studies reported that selenium was associated with some other mineral elements, including arsenic, cadmium and lead (Tian et al., 2016), and these heavy metal elements were classified as heavy metal type I. Other heavy metal elements, which are not associated with mineral elements and may cause heavy metal pollution in local areas, were classified as heavy metal type II. These elements, which were chosen as evaluation indexes, would be selected according to an investigation into heavy metal elements in the study area.

\subsection{Weight determination}

By using the Delphi method and a questionnaire survey, the opinions of experts and scholars were collected (Vidal et al., 2011). Participants assessed pairs of elements in the same layer based on their relative importance to the upper hierarchy. Then, experts and scholars determined their relative importance of the element and gave corresponding scores according to 9-point scales respectively (Saaty, 2000). In this way, the importance was transformed into the corresponding numerical value and the judgment matrix was constructed.
The judgment matrix was normalized first, and then the eigenvalues and eigenvectors of the normalized matrix were calculated to find the maximum eigenvalue. The consistency ratio (CR) was utilized to verify the consistency of the judgment matrix (Hsu et al., 2008). The consistency of the judgment matrix was checked. When $\mathrm{CR}$ was $<0.1$, it was considered that the single level judgment matrix had satisfactory consistency (Kang and Seong, 1999; Kaya and Kahraman, 2010). If the consistency test passed, the weight of each index was obtained. If the consistency test failed to pass, the judgment matrix continued to be coordinated till it meets the consistency check. For the criteria layer, CR was computed firstly and checked whether it passed the consistency test. In addition, the corresponding weight of each element in the criteria layer was determined. Using the same method and steps, the respective judgment matrixes of soil fertility and environmental quality were constructed. Afterwards, the respective eigenvalues and eigenvectors were obtained to check whether the value of their CR met the consistency test. If the results of all judgment matrices are acceptable through consistency test, the consistency check of total sequencing of each level is applied. With satisfactory consistency, each index weight of the comprehensive environmental selenium resources regional evaluation was confirmed.

\subsection{Standardization of evaluation index and calculating comprehensive index}

Applying multi-indicators assessment, the comprehensive analysis and assessment was difficult to conduct because indicators had different dimensions and the values of different indexes also had relatively large differences. Therefore, the data of each evaluation index needed to be dimensionless. The min-max normalization method was adopted to eliminate effects of different dimension (Du, 2016; Yin, 2013). When the concentration of selenium in surface soils was below $3 \mathrm{mg} / \mathrm{kg}$, the 
index of selenium resources was regarded as the positive indicator, which was standardized using formula (1). When the concentration of selenium in surface soils was above $3 \mathrm{mg} / \mathrm{kg}$, the measured value was standardized by formula (3). This conversion guaranteed the zones obtained very low comprehensive scores because selenium may cause adverse effects on crops and pollute the soils when concentrations were $>3 \mathrm{mg} / \mathrm{kg}$ (Tan et al., 1987). Indexes of soil fertility were seen as positive indicators, which were standardized using formula (1). The concentrations of various pollutants in the soil environment were regarded as negative indicators, which were transformed using formula (2). The more serious the pollution, the smaller the value.

$\mathrm{R}_{\mathrm{i}}=\frac{\mathrm{X}_{\mathrm{i}}-\mathrm{X}_{\min }}{\mathrm{X}_{\max }-\mathrm{X}_{\min }} \times 100$

$\mathrm{R}_{\mathrm{i}}=\frac{\mathrm{X}_{\max }-\mathrm{X}_{\mathrm{i}}}{\mathrm{X}_{\max }-\mathrm{X}_{\min }} \times 100$

$\mathrm{R}_{\mathrm{i}}=\frac{0.375 / \mathrm{X}_{\mathrm{i}}-\mathrm{X}_{\min }}{\mathrm{X}_{\mathrm{i} \max }-\mathrm{X}_{\mathrm{i} \min }} \times 100$

i represents sample serial number; $R_{i}$ is non-dimensionalized value after conversion by min-max normalization method; $\mathrm{x}_{\mathrm{i}}$ is the $\mathrm{i}^{\text {th }}$ measured value, $x_{\max }$ is the maximum of all measured values, $x_{\min }$ is the minimum of all measured values.

According to the weights and the dimensionless value of each evaluation factor, a comprehensive index (D) was calculated in evaluation units. The composite index was calculated following formula (4). The larger the comprehensive index (D), the corresponding zones were more suitable for developing selenium-rich agriculture. Calculating comprehensive evaluation indexes, classifying grades and drawing maps were all operated in ArcGIS 10.2 for windows 10.

$\mathrm{D}=\sum \mathrm{W}_{\mathrm{i}} \mathrm{R}_{\mathrm{i}}$

i represents sample serial number; $\mathrm{D}$ represents the comprehensive evaluation index; $\mathrm{R}_{\mathrm{i}}$ is nondimensionalized value after conversion by min-max normalization method; $\mathrm{W}_{\mathrm{i}}$ is corresponding weights.

\subsection{Comprehensive evaluation criteria}

The critical values in quality standards, soil fertility criteria and ecological landscape classification of selenium (Table S1, in supplementary material) were selected to calculate new critical values for comprehensive assessment (Tan et al., 1987; National Soil Survey Office, 1992; State Standard of China, 2006; Sun et al., 2016). The critical values in original standards were non-dimensionalized because the dimension of different indexes is different. The new critical values of a comprehensive evaluation system of regional selenium resources were calculated by summing standardized critical values with corresponding weights, as shown in the following formula (5).

$\mathrm{S}=\sum \mathrm{W}_{\mathrm{i}} \mathrm{C}_{\mathrm{i}}$

i represents sample serial number; $S$ represents critical values of comprehensive evaluation system of regional selenium resources. $C_{i}$ is the nondimensionalized critical value after conversion by min-max normalization method; $\mathrm{W}_{\mathrm{i}}$ is the corresponding weight.

This criterion for the specific classification followed the principles that we considered as below. In zone I, soils must be clean and processed with rich selenium resources and high fertility, which is recommended for developing selenium-rich agriculture. The region, which was detected with pollutants exceeding environmental quality standard, was directly assigned into rank $\mathrm{V}$. The areas, in which selenium content exceeded $3 \mathrm{mg} / \mathrm{kg}$, were also sorted into rank V. Selenium may cause diseases and toxicity when it is in soils beyond $3 \mathrm{mg} / \mathrm{kg}$ or goes below $0.125 \mathrm{mg} / \mathrm{kg}$ (Tan et al., 1987, Tan and Zhu, 1989). The classification from II to IV was mainly based on critical values for comprehensive assessment. Zone II and III were allowed to develop selenium-rich agriculture, while Zone IV was not suitable to develop selenium-rich agriculture. Based on the cited standards with a five level ordinal scale, the comprehensive evaluation system of regional selenium resources was classified into 5 grades (Table 1 ).

\section{Case study on comprehensive assessment of regional selenium resources}

\subsection{General situation of case area}

Boshan was taken as a case area, as it is regarded as a representative base for developing selenium-rich agriculture in North China. The average content of selenium in this area is $0.305 \mathrm{mg} / \mathrm{kg}$, which is slightly higher than the national average $(0.290 \mathrm{mg} / \mathrm{kg})$. The case area is Boshan district, located in Zibo city, Shangdong province, China, which lied between the north latitude $36^{\circ} 16^{\prime}-36^{\circ} 31^{\prime}$ and the east longitude $117^{\circ} 43^{\prime}-$ $118^{\circ} 42^{\prime}$ (Fig. 2). The total area of Boshan district is $698.2 \mathrm{~km}^{2}$. The general terrain is highlands in the South and lowlands in the North. The northern terrain is mostly hilly with valleys and mid-low mountains located in the eastern, western and southern parts. In Boshan, the 4 main rivers are Zi River, Xiaofuhe River, Qingyang River and Niujiao River, from which farmland can be irrigated. The average annual precipitation in this region is $736.6 \mathrm{~mm}$ and the maximum precipitation occurs during the summer. The annual temperature ranged from $-2.2{ }^{\circ} \mathrm{C}$ to $27.5^{\circ} \mathrm{C}$ and the average annual temperature was $13.6^{\circ} \mathrm{C}$.

\subsection{Sample collection and analysis}

The sampling process used the uniform grid method with a $3 * 3 \mathrm{~km}$ grid in the Boshan area (Fig. 2). The surface soils $(0-20 \mathrm{~cm})$ were collected and the total number of samples was 61 . GPS was used to locate the sample and the soil samples were taken back to the laboratory and dried in the shade. In order to obtain the relevant data, physical and chemical properties of soils, the content of selenium, heavy metals and polycyclic aromatic hydrocarbons (PAHs) were analyzed for all samples. Pesticides (DDTs and HCHs) were analyzed for 16 samples in the agricultural region and the spatial interpolation method was used in the rest of the case area to obtain corresponding content of pesticides (DDTs and HCHs).

The contents of selenium in surface soils were determined by microwave digestion and the atomic fluorescence method. No selenium was detected in blank control and analytical quality control was used in this experiment. In order to guarantee the accuracy, the national standard soil reference (GSS-3) was also analyzed and the measured mean of selenium content was $0.093 \mathrm{mg} \cdot \mathrm{kg}^{-1}$, which showed that the measured data were reliable. The soil sample was firstly heated by oil bath and the potassium dichromate titration method was used to determine total organic carbon (TOC) content. Total nitrogen (TN) in the soil samples was determined by elemental analysis instrument. After pretreatment, the content of clay was measured using laser particle size

Table 1

Classification criteria of a comprehensive evaluation system of regional selenium resources.

\begin{tabular}{lll}
\hline Classification & S & Features \\
\hline I & $>60$ & Recommend for the development of selenium-rich agriculture \\
II & $32-60$ & Relative suitable for development of selenium-rich agriculture \\
III & $24-32$ & Allow the development of selenium-rich agriculture \\
IV & $18-24$ & Not recommended for selenium-rich agriculture \\
V & $<18$ & Forbid the development of selenium-rich agriculture \\
\hline
\end{tabular}

$\mathrm{S}$ represents critical values of comprehensive evaluation system of regional selenium resources. 


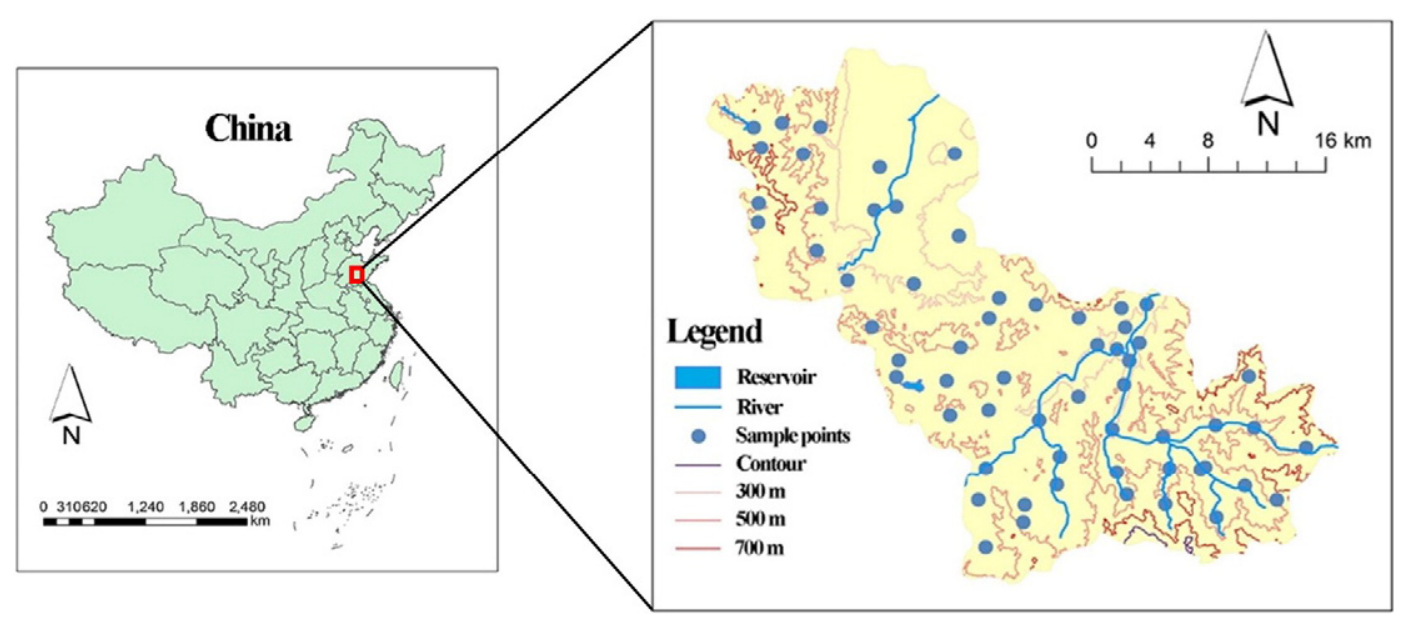

Fig. 2. Location of case area and sampling distributions.

analyzer. The concentrations of heavy metal elements were measured using microwave digestion and inductively coupled plasma mass spectrometry (ICP-MS). Determination of DDTs and HCHs was measured by gas chromatography and polycyclic aromatic hydrocarbons (PAHs) were determined by liquid chromatography. In the above measurement process, the quality control was carried out by using control groups, parallel samples and standard samples.

\subsection{Questionnaire survey}

Based on the comparative importance using AHP, questionnaires were designed to determine the weight of the indexes. Before answering the questionnaire, participants were informed about the soil investigation data of Boshan, including selenium content, soil nutrients and pollutant contents. Experts and scholars were invited to fill in questionnaires about factors comprising the criterion layer and index layer in pairs by the Delphi method. According to the degree of importance, the corresponding scores were obtained and the judgment matrix was constructed. Twenty questionnaires were distributed to experts and scholars with knowledge of selenium, and twenty questionnaires were distributed to experts and scholars with knowledge of soil science. Another twenty questionnaires were distributed to specialists in environmental science. A total of 60 questionnaires were collected and the number of valid questionnaires was 52 .

\subsection{Hierarchical structure and calculation of weights}

The results of comparing the relative importance of the criteria layer elements are shown in Table 2. The judgment matrix of each sub layer was derived by following the same method and procedure (Table 3). According to the judgment matrix, the Yaahp software was used to calculate the weight (Chen and Shen, 2012; Nie et al., 2013; Wu et al., 2014). After a series of calculations, the CR of the criteria layer was 0.0089 , which is $<0.1$ and satisfied the consistency test.

According to the analytic hierarchy process, hierarchical structure was established as shown in Table 4. This assessment system consists of 1 target layer (A), the 3 criteria layers (B) and the 9 index layer (C). Weights of each index were also determined in Table 4.

Table 2

Results of comparing relative importance in criteria layer(B).

\begin{tabular}{llll}
\hline & Selenium resources & Soil fertility & Environmental quality \\
\hline Selenium resources & 1 & 3 & 2 \\
Soil fertility & $1 / 3$ & 1 & $1 / 2$ \\
Environmental quality & $1 / 2$ & 2 & 1
\end{tabular}

\subsection{Measured data of assessment indicators}

Measured data of each sample were presented in Fig. 3. All the measured values of selenium content were $<3 \mathrm{mg} / \mathrm{kg}$ and selenium was beneficial to agricultural production (Fig. 3(a)). Most measured data of TOC ranged from 0 to $2 \mathrm{~g} / \mathrm{kg}$ (Fig. 3(b)). Five samples had a relatively high content of TOC, which implied high organic matter content in these areas. As shown in Fig. 3(c), TN concentration was 0.5 and $1.5 \mathrm{~g} / \mathrm{kg}$. The soil types in the case area were loam and clay (Fig. 3(d)). The phenomenon that pollutants exceed the environmental quality standard occurred in a few areas in Boshan and the pollutants were heavy metal $\mathrm{Cd}$ and PAHs. HCHs and DDTs were also beyond the limit of farmland environmental quality evaluation standard for edible agricultural products in fractions of Boshan (State Standard of China, 2006). This pollution problem may be caused by pesticide residues (Fig. 3(h) and (i)). Although HCHs and DDTs have been banned for many years, they were slow to degrade in the natural environment.

\subsection{Evaluation results and suggestions}

The evaluation results of each criterion layer are shown in Fig. 4. As shown in Fig. 4(a), the content of selenium had a decreasing tendency from north to south in the case area. The selenium content was affected by many factors, including selenium content in soil parent material, physical and chemical properties of soils. Previous studies reported that selenium was accompanied with mineral elements (Chen et al.,

Table 3

Results of comparing relative importance in index layer(C).

\begin{tabular}{lllllllll}
\hline & TOC & TN & Clay & $\mathrm{Cd}^{\text {a }}$ & $\mathrm{Cr}^{\mathrm{b}}$ & PAHs & HCHs & DDTs \\
\hline TOC & 1 & & & & & & & \\
TN & $1 / 4$ & 1 & & & & & & \\
Clay & $1 / 3$ & 2 & 1 & & & & & \\
Cd $^{\mathrm{a}}$ & & & & 1 & & & & \\
$\mathrm{Cr}^{\mathrm{b}}$ & & & & $1 / 5$ & 1 & & & \\
PAHs & & & & $1 / 3$ & $1 / 3$ & 1 & & \\
HCHs & & & & $1 / 3$ & $1 / 2$ & 3 & 1 & 1 \\
DDTs & & & & $1 / 4$ & $1 / 2$ & 3 & 1 & 1
\end{tabular}

${ }^{a}$ Cd was chosen as a representative for heavy metal type I in the case study. Heavy metal type I represents the heavy metals, which may be accompanied with mineral elements in soils, are likely to cause pollution. The content of $\mathrm{Cd}$ is significantly correlated to the content of Se in the case area;

b $\mathrm{Cr}$ was chosen as a representative for heavy metal type II in the case area. Heavy metal type II represents other heavy metals, which would cause pollution. The content of $\mathrm{Cr}$ is uncorrelated to the content of Se and its content is relatively more than other heavy metals. 
Table 4

Comprehensive evaluation system of regional selenium resources and corresponding weights.

\begin{tabular}{|c|c|c|c|c|c|}
\hline Target layer & Criterion layer & Weight & $\begin{array}{l}\text { Index } \\
\text { layer }\end{array}$ & Weight & $\begin{array}{l}\text { Total } \\
\text { sequencing } \\
\text { weight }\end{array}$ \\
\hline \multirow{9}{*}{$\begin{array}{l}\text { Comprehensive } \\
\text { evaluation system of } \\
\text { regional selenium } \\
\text { resources }\end{array}$} & $\begin{array}{l}\text { Selenium } \\
\text { resources }\end{array}$ & 0.539 & Se & 1.000 & 0.539 \\
\hline & Soil fertility & 0.164 & TOC & 0.623 & 0.102 \\
\hline & & & $\mathrm{TN}$ & 0.137 & 0.023 \\
\hline & & & Clay & 0.240 & 0.039 \\
\hline & Environmental & 0.297 & $\mathrm{Cd}^{\mathrm{a}}$ & 0.454 & 0.135 \\
\hline & quality & & $\mathrm{Cr}^{\mathrm{b}}$ & 0.195 & 0.058 \\
\hline & & & PAHS & 0.073 & 0.022 \\
\hline & & & $\mathrm{HCHs}$ & 0.143 & 0.042 \\
\hline & & & DDTs & 0.135 & 0.040 \\
\hline
\end{tabular}

a $\mathrm{Cd}$ was chosen as a representative for heavy metal type I in the case study. Heavy metal type I represents the heavy metals, which may be accompanied with mineral elements in soils, are likely to cause pollution. The content of $\mathrm{Cd}$ is significantly correlated to the content of Se in the case area;

${ }^{b} \mathrm{Cr}$ was chosen as a representative for heavy metal type II in the case area. Heavy metal type II represents other heavy metals, which would cause pollution. The content of $\mathrm{Cr}$ is uncorrelated to the content of Se and its content is relatively more than other heavy metals.

2015). Our previous study found that Se in soils of Boshan was significantly correlated with $\mathrm{Cd}$. There were hundreds of coal mines in the midlands of Boshan in the past few decades. The extraction of coal may accelerate weather of Se-bearing rocks, which led to higher concentration in soils (Ryser et al., 2006). Considering the overall region, northern areas had been higher fertility of soils than the south
(Fig. 4(b)). In western zones, the soils were clean and fertile but the selenium content was low, which suggested this region was used for agricultural land uses. In the northeast zones for urban and industrial land uses, the environmental quality was relatively poor (Fig. 4(c)), which may cause soil pollution due to the release of pollutants from domestic and industrial activities. The environmental quality was also relatively poor in several parts of the southern areas, especially in southeast zones. This pollution may have been caused by continued overuses of pesticides in the farmlands.

The results of comprehensive evaluation of regional selenium resources in Boshan are shown in Fig. 5. Zone I was the most suitable for developing selenium-rich agriculture, which was $1.92 \mathrm{~km}^{2}$. This area is rich in selenium resources, with clean and fertile land, which was recommended for the development of selenium-rich agriculture. Zone II was $258.44 \mathrm{~km}^{2}$ and accounted for $37.02 \%$ of total area, and is mainly distributed in western and northern zones. Zone II was relatively suitable for the development of selenium-rich agriculture because selenium content was relatively high and soil nutrients are abundant. Zone III occupied the largest area in Boshan $\left(393.72 \mathrm{~km}^{2}\right)$. In this region, selenium content reached an adequate level. However, to develop selenium-rich agriculture in Zone III (393.72 $\mathrm{km}^{2}, 56.39 \%$ of total area), seleniumrich agriculture will be developed only by applying exogenous selenium fertilizer. Zone IV covered $42.23 \mathrm{~km}^{2}$ and accounted for $6.07 \%$ of total area in Boshan. The soils in this area are relatively clean, which complies with Chinese soil environmental quality standard. However, the selenium content and soil fertility are relatively low in the soils of Zone IV, which is not suitable for developing selenium-rich agriculture. It is suggested that pioneer and accompanying species may be developed in Zone IV. Zone V was $1.89 \mathrm{~km}^{2}$ and accounted for $0.3 \%$ of total area.
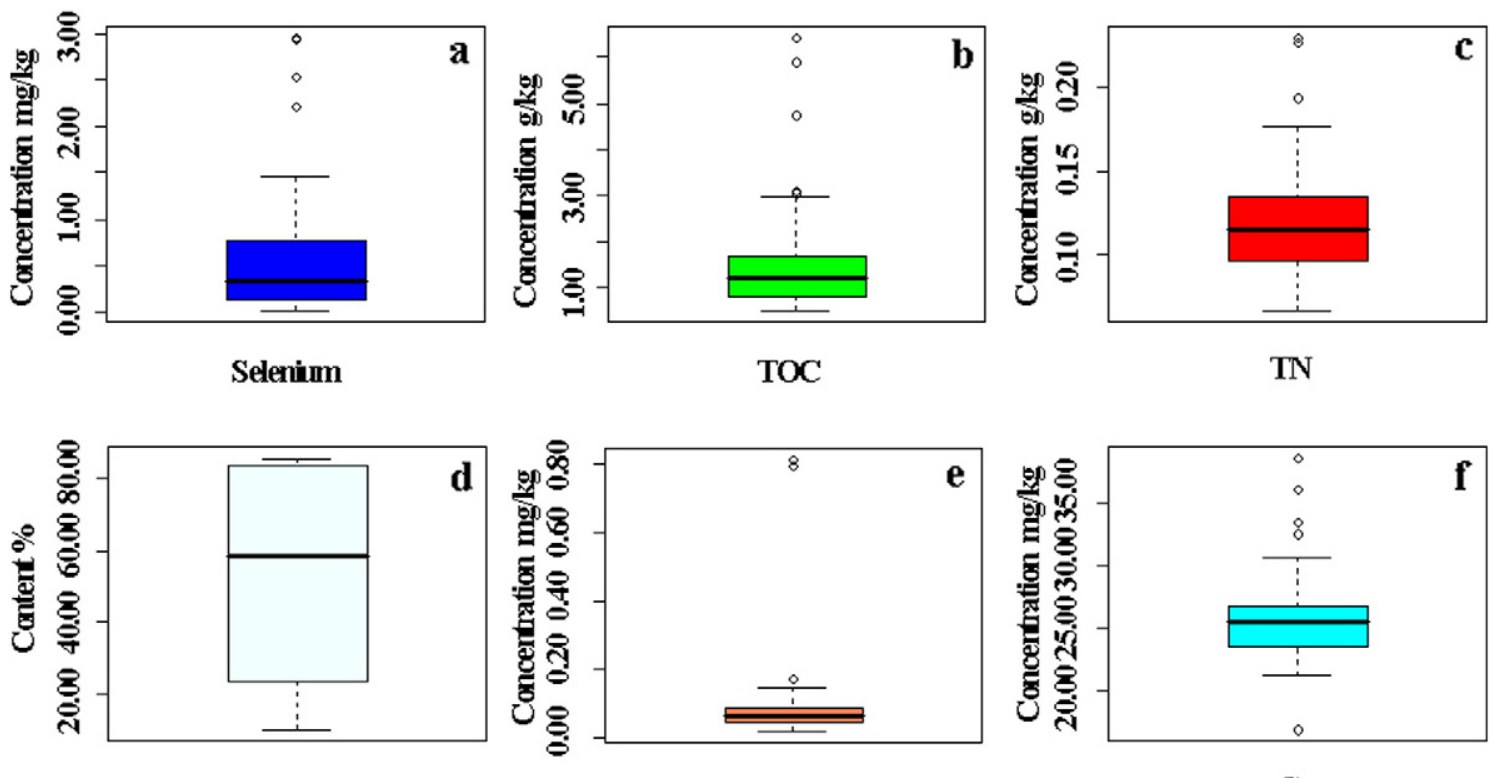

Clay

Cd
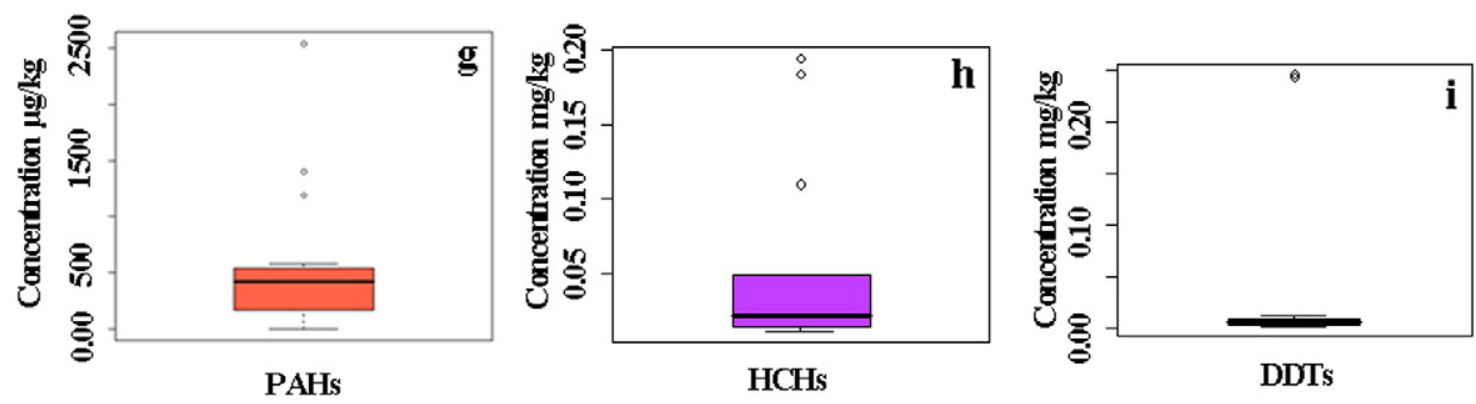

Fig. 3. Measured data of assessment indicators. 

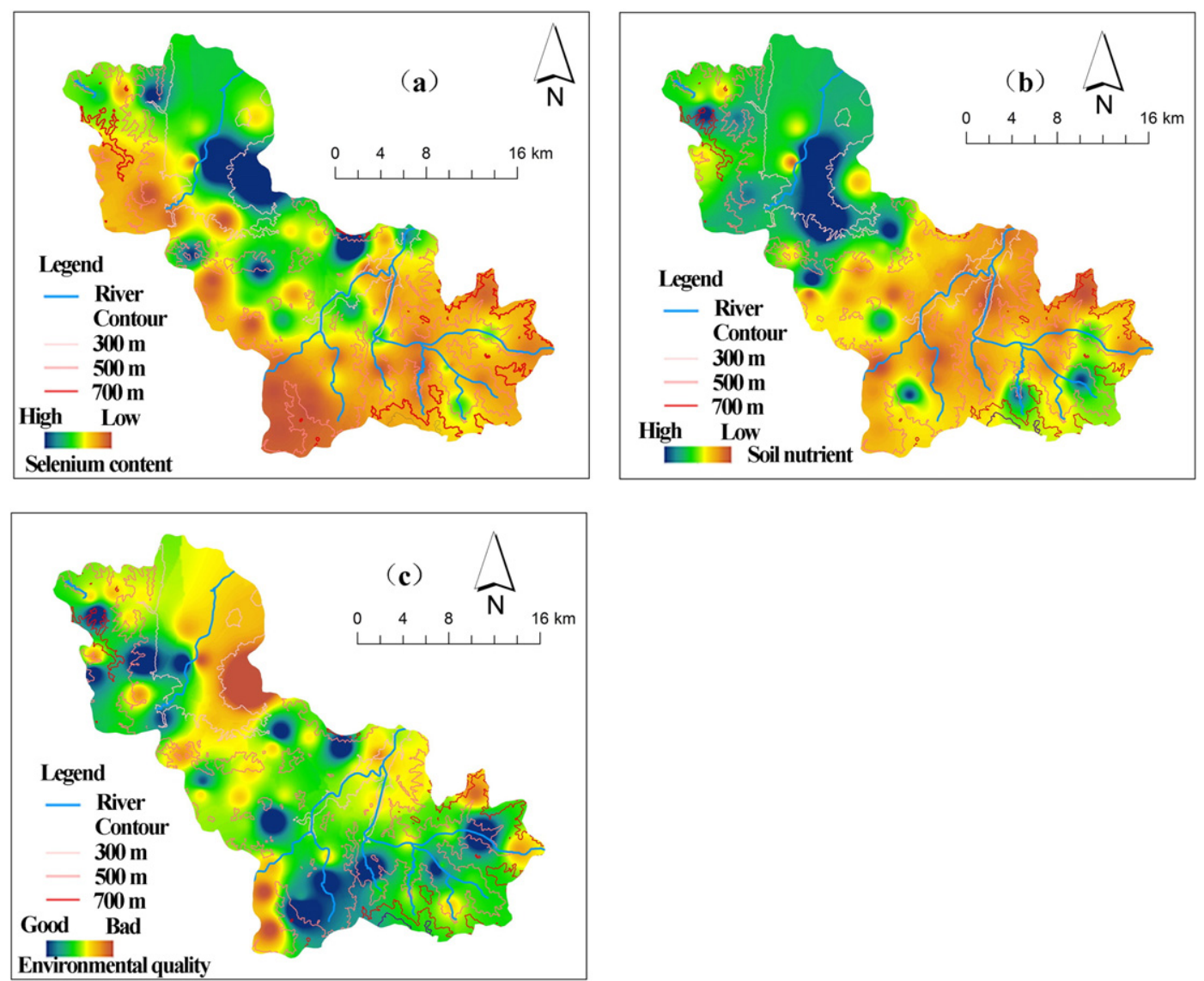

Fig. 4. Assessment results of selenium resources (a), soil nutrient (b) and environmental quality (c) in Boshan.

Selenium-rich agriculture was forbidden in Zone V, which comprised small fractions located in south zones. Low selenium content was detected in these fractions. In addition, the land was impoverished and polluted. This pollution problem may have been caused by heavy metal Cd, PAHs, HCHs and DDTs. If we want to develop agriculture in this region, it will be necessary to recover and remediate the pollution in soils as soon as possible. The assessment results suggested that only $6.37 \%$ of the land was totally unsuitable or forbidden to develop selenium-rich agriculture. Selenium-rich agriculture could be developed in most areas, especially in the North and Midlands.

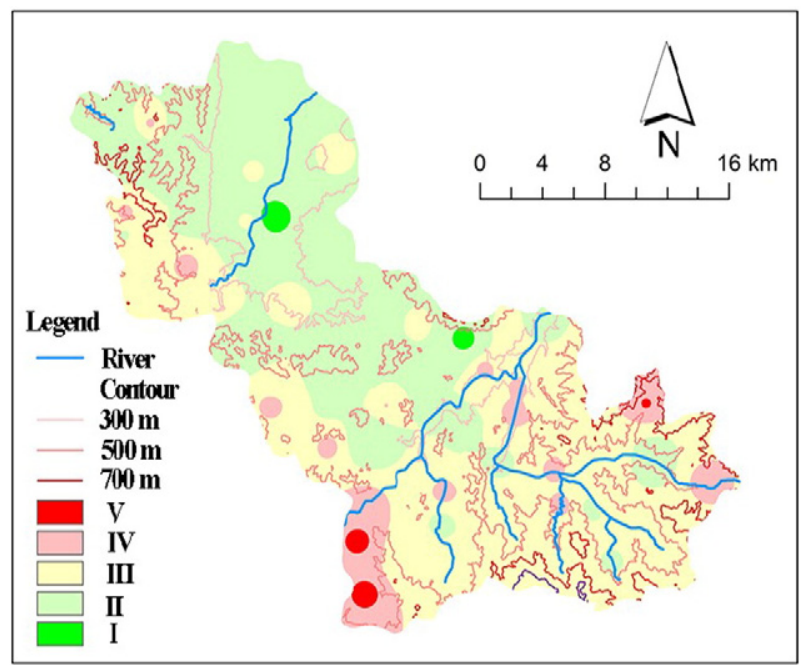

Fig. 5. Comprehensive assessment of regional selenium resources in Boshan. (I-V represent different grades of the comprehensive assessment).

\section{Conclusions}

Boshan in Shandong province, China was taken as a case area, which was classified and graded in this research considering selenium, nutrients and environmental quality in soils. Zone I and II are suitable to develop selenium-rich agriculture, which accounts for $37.2 \%$ of the total area in Boshan. Zone III can develop selenium-rich agriculture by adding fertilizer of selenium into farmlands. Zone $V$ accounted for $1.89 \mathrm{~km}^{2}$, and it is forbidden to develop agriculture due to pollution in soils exceeding the criteria. The heavy mental $\mathrm{Cd}$, PAHs, $\mathrm{HCH}$ s and DDTs in fractions are significant responsible pollutants of Boshan. These pollutants remained in soils, which may have been caused by the abuse of pesticides and industrial pollution in the past. This assessment for selenium resources in the case area was expected to provide the basis for selenium-rich agriculture and also for regional planning of Boshan.

Taking comprehensive consideration of selenium resources, soil nutrient and environmental quality, the comprehensive assessment system of regional selenium resource was established based on analytic hierarchy process, which was expected to provide scientific support for the development of local agriculture. This study provides an example of the evaluation of regional selenium resources, although the methods and criteria for assessing selenium resources still need to be further investigated and refined.

\section{Acknowledgements}

The authors are grateful for the support provided by Special Fund for Agro-scientific Research in the Public Interest (Grant No.201303106), the National Natural Science Foundation of China (Grant No. 41671483; No. 414201040045) and the National R\&D Program (2017YFC0505704). 


\section{Appendix A. Supplementary data}

Supplementary data to this article can be found online at http://dx. doi.org/10.1016/j.scitotenv.2017.06.150.

\section{References}

Alphonce, C.B., 1997. Application of the analytic hierarchy process in agriculture in developing countries. Agric. Syst. 53, 97-112.

Borowska, K., Kozik, K., Grabowska, M., 2013. Seasonal Changes of Selenium and Selected Oxidoreductases in Soil Under Manure and Nitrogen Fertilization. Towarzystwo Chemii I Inżynierii Ekologicznej.

BY, M., XL, Z., 2000. Regional ecological risk assessment of selenium in Jilin province, China. Sci. Total Environ. 262, 103.

Chen, J., Shen, X.X., 2012. The applications of analytic hierarchy process in house purchase decision-making and its implementations in yaahp software. Journal of Liaoning Teachers College 1, 317-337.

Chen, J., Song, S., Shi, Y.J., Xu, X.B., Sun, H.J., Lu, L.L., 2015. Spatial distributon and assessment of selenium in soils of a Se-rich agricultural production base. Environ. Chem. 34, 2185-2190 (in Chineses, with English abstract).

De Temmerman, L., Waegeneers, N., Thiry, C., Du Laing, G., Tack, F., Ruttens, A., 2014. Selenium content of Belgian cultivated soils and its uptake by field crops and vegetables. Sci. Total Environ. 468-469, 77-82.

Du, J., Chen, Y., 2016. Ecosystem health evaluation of oasis-desert ecotone in Minqin County based on PSR model. Research of Soil \& Water Conservation.

Gergen, I., Harmanescu, M., 2012. Application of principal component analysis in the pollution assessment with heavy metals of vegetable food chain in the old mining areas. Chem. Cent. J. 6, 156.

Hajeeh, M., Al-Othman, A., 2005. Application of the analytical hierarchy process in the selection of desalination plants. Desalination 174, 97-108.

Hatfield, D.L., Tsuji, P.A., Carlson, B.A., Gladyshev, V.N., 2014. Selenium and selenocysteine: roles in cancer, health and development. Trends Biochem. Sci. 39, 112.

Hsu, P.F., Wu, C.R., Li, Y.T., 2008. Selection of infectious medical waste disposal firms by using the analytic hierarchy process and sensitivity analysis. Waste Manag. 28 1386-1394.

Hughes, D.J., Fedirko, V., Jenab, M., Schomburg, L., Méplan, C., Freisling, H., et al., 2015. Selenium status is associated with colorectal cancer risk in the European prospective investigation of cancer and nutrition cohort. Int. J. Cancer 136, 1149-1161.

Johnsson, L., 1991. Selenium uptake by plants as a function of soil type, organic matter content and pH. Plant Soil 133, 57-64.

Kang, H.G., Seong, P.H., 1999. A methodology for evaluating alarm-processing systems using informational entropy-based measure and the analytic hierarchy process. IEEE Trans. Nucl. Sci. 46, 2269-2280.

Kaya, T., Kahraman, C., 2010. Multicriteria renewable energy planning using an integrated fuzzy VIKOR \& AHP methodology: the case of Istanbul. Energy 35, 2517-2527.

Khan, S., Cao, Q., Zheng, Y.M., Huang, Y.Z., Zhu, Y.G., 2008. Health risks of heavy metals in contaminated soils and food crops irrigated with wastewater in Beijing, China. Environ. Pollut. 152 (686)

Li, Y.H., Li, L.Q., Pan, G.X., Liao, Q.L., Wu, X.M., 2006. Variation of soil selenium in some croplands in Yixing and its influencing factors. Journal of Ecology and Rural Environment 22, 61-64 (in Chineses, with English abstract).

Li, J., Peng, Q., Liang, D., Liang, S., Chen, J., Sun, H., et al., 2016. Effects of aging on the fraction distribution and bioavailability of selenium in three different soils. Chemosphere $144,2351-2359$.

Listed, N., 1979. Observations on effect of sodium selenite in prevention of Keshan disease. Chin. Med. J. 92, 471-476.

Loscalzo, J., 2014. Keshan disease, selenium deficiency, and the selenoproteome. N. Engl. J. Med. 370, 1756.

National Soil Survey Office, 1992. Chinese Soil Survey Technique. Agricultural Press, Beijing.

Nie, Y.L., Zhai, Y.L., Wang, Y.H., 2013. On the rearrangement potentiality of regional agricultural land based on the AHP method by Yaahp software: a case study on Jialing District. Journal of China West Normal University.
Ryser, A.L., Strawn, D.G., Marcus, M.A., Fakra, S., Johnson-Maynard, J.L., Möller, G., 2006. Microscopically focused synchrotron X-ray investigation of selenium speciation in soils developing on reclaimed mine lands. Environ. Sci. Technol. 40, 462.

Saaty, T.L., 1980. The Analytic Hierarchy Process: Planning, Priority Setting, Resource Allocation. McGraw-Hill, NY, USA.

Saaty, T.L., 2000. Fundamentals of decision making and priority theory with the analytic hierarchy process. Analytic Hierarchy Process.

Saaty, T.L., 2005. Theory and Applications of the Analytic Network Process: Decision Making with Benefits, Opportunities, Costs, and Risks. RWS Publications.

Saaty, T.L., 2008. Decision making with the analytic hierarchy process. International Journal of Services Sciences 1, 83-98.

Shen, G., Lu, Y., Wang, M., Sun, Y., 2005. Status and fuzzy comprehensive assessment of combined heavy metal and organo-chlorine pesticide pollution in the Taihu Lake region of China. J. Environ. Manag. 76, 355-362.

Skalny, A, Burtseva, T.I. 2015. Ecological assessment of selenium deficiency risk in population of the Orenburg region. The International Selenium Seminar «Selenium: Biology, Clinical and Preventive Medicine, Nutrition», Yaroslavl.

State Standard of China, 2006. Environmental Quality Evaluation Standards for Farmland of Edible Agricultural Products (HJ 332-2006) (Beijing, China).

Stolzoff, M., Webster, T.J., 2015. Reducing bone cancer cell functions using selenium nanocomposites. J. Biomed. Mater. Res. A 104, 476-482.

Sun, J., Chen, Q.G., Long, R.J., Jang, W.L., 2009. Assessment of selenium pollution in agricultural soils in the Xuzhou District, Northwest Jiangsu, China. J. Environ. Sci. 21, 481-487.

Sun, L., Liao, X., Yan, X., Zhu, G., Ma, D., 2014. Evaluation of heavy metal and polycyclic aromatic hydrocarbons accumulation in plants from typical industrial sites: potential candidate in phytoremediation for co-contamination. Environ. Sci. Pollut. Res. 21, 12494-12504.

Sun, Y, Oi, S.H. Li, H., Huang, H.F. Yang D., Fan, Y.H., Zhai, C.C., 2016. Concentrations, sources and health risk assessment of polycyclic aromatic hydrocarbons in soils collected along the banks of Minjiang River, Fujian, China. China Environ. Sci. 36 (6), 1821-1829.

Supriatin, S., Weng, L., Comans, R.N., 2015. Selenium speciation and extractability in Dutch agricultural soils. Sci. Total Environ. 532, 368-382.

Supriatin, S., Weng, L., Comans, R.N.J., 2016. Selenium-rich dissolved organic matter determines selenium uptake in wheat grown on low-selenium arable land soils. Plant Soil 1-22.

Tan, J.A., Zhu, W., 1989. Chemical endemic diseases and their impact on population in china. J. Environ. Sci. 107-114.

Tan, J.A., Wang, W.Y., Zhu, Z.Y., Wang, L.Z., Lu, Y.L., 1987. Environmental selenium with its compound factors and Kashin Beck disease. Acta Sci. Circumst. 7, 8-13 (in Chineses).

Tian, H., Ma, Z., Chen, X., Zhang, H., Bao, Z., Wei, C., et al., 2016. Geochemical characteristics of selenium and its correlation to other elements and minerals in seleniumenriched rocks in Ziyang County, Shanxi Province, China. J. Earth Sci. 27, 763-776.

Tolu, J., Le Hécho, I., Bueno, M., Thiry, Y., Potin-Gautier, M., 2011. Selenium speciation analysis at trace level in soils. Anal. Chim. Acta 684, 126-133.

Vahidnia, M.H., Alesheikh, A.A., Alimohammadi, A., 2009. Hospital site selection using fuzzy AHP and its derivatives. J. Environ. Manag. 90, 3048.

Vidal, L.A., Marle, F., Bocquet, J.C., 2011. Using a Delphi process and the Analytic Hierarchy Process (AHP) to evaluate the complexity of projects. Expert Systems with Applications an International Journal 38, 5388-5405.

Wang, G., Qin, L., Li, G., Chen, L., 2009. Landfill site selection using spatial information technologies and AHP: a case study in Beijing, China. J. Environ. Manag. 90, 2414-2421.

Wu, W.G., Zhang, J.H., Wei, Y.W., Fang, J.G., 2014. The ecological risk assessment of Bullacta exarata in Laizhou Bay: the YAAHP software implementation based on AHP. J. Fish. China.

Yang, L.C., Li, M.L., Chen, L., Xu, K.Y., YIN, Y.C., 2016. Geochemical characteristics of Se in farmland soil of Enshi. Resources Environment \& Engineering 30, 852-855 (in Chineses, with English abstract).

Yin, Y., 2013. Sensor-oriented feature usability evaluation in fingerprint segmentation. Opt. Eng. 52, 067201.

Zhang, H.H., Wu, Z.F., Yang, C.L., Xia, B., Xu, D.R., Yuan, H.X., 2008. Spatial distributions and potential risk analysis of total soil selenium in Guangdong Province, China. J. Environ. Qual. 37, 780. 